\title{
Fatigue strength analysis of bogie frame in consideration of parameter uncertainty
}

\author{
Bingzhi Chen, Pengpeng Zhi \\ School of Mechanical Engineering, Dalian Jiaotong University, Dalian 116028, China, \\ chenbingzbi06@hotmail.com, zhipeng17@yeah.net
}

Yonghua Li

School of Locomotive and Rolling Stock Engineering, Dalian Jiaotong University, Dalian 116028, Cbina, yonghuali@163.com

ABSTRACT. In this paper, a fatigue strength analysis approach based on Goodman-Smith fatigue limit diagram (GSFLD) and reliability theory is proposed to solve the problem that the traditional fatigue strength analysis of bogie frame is too conservative, considering the parameter uncertainty in engineering practice. Firstly, according to UIC615-4, EN13749 standard and GSFLD, the fatigue strength of the frame is calculated. The experimental results are compared with the simulation data to determine the location of the maximum fatigue strength as the control point for the strength evaluation. Secondly, the parametric model of the frame is established by ANSYS parametric design language (APDL) language, and the D-optimal experiment design of uncertainty parameters is carried out. The polynomial response surface function with the mean stress and stress amplitude of the control point as the objective is established. The control points under the influence of uncertainty parameters are obtained by importance sampling method. Finally, the functional expression of GSFLD without considering the safety factor is derived, and the fatigue strength reliability of control point is calculated. The results of this study not only reveal the influence of parameter uncertainty on fatigue strength, but also demonstrate a need of developing new evaluation methods to accommodate fatigue analysis.

KEYWORDS. Bogie frame; Fatigue strength; Goodman-Smith fatigue limit diagram; Response surface; Fatigue reliability.

\section{OPEN ACCESS}

Citation: Chen, B., Zhi, P., Li, Y., Fatigue strength analysis of bogie frame in consideration of parameter uncertainty, Frattura ed Integrità Strutturale, 48 (2019) $385-399$.

Received: 23.01 .2019

Accepted: 26.02 .2019

Published: 01.04.2019

Copyright: (C) 2019 This is an open access article under the terms of the CC-BY 4.0, which permits unrestricted use, distribution, and reproduction in any medium, provided the original author and source are credited.

\section{INTRODUCTION}

ogie frame is the base of carrying and transferring forces of many structural parts in the running gear of train. Its reliability plays an important role in the safety and stability of train operation. However, as a large plate welding member, the evaluation of its structural reliability is essentially to check the structural strength and fatigue strength 
after welding. With the continuous improvement of train operation speed, the fatigue failure of the structure is particularly prominent. In the fracture accidents of the frame, most of them are caused by fatigue failure. Therefore, it is more important to accurately evaluate the fatigue strength of the frame than the structural strength. At present, the research on fatigue strength of bogie frame is mainly based on two aspects: dynamics and statics. Dynamics-based research, the dynamic model of multi-rigid-body system of vehicle body is established by analyzing the irregularity of track line, and the load history of vehicle suspension system is obtained. On this basis, the dynamic analysis and stress evaluation of the bogie are carried out, and the fatigue life of the bogie is predicted according to the cumulative damage theory. The difference lies in that different scholars consider different contents in the construction of dynamic model and fatigue life evaluation [1-4]. Statics-based research, researchers mainly use finite element method (FEM) to simulate the load of bogie frame in operational condition and determine the location to be evaluated. Then, the fatigue strength is evaluated based on fatigue limit diagram [5-8]. The difference between the two methods is that the static fatigue strength assessment is based on the fatigue limit diagram and standard loads. The dynamic fatigue strength assessment is based on the measured stress spectrum, and the fatigue life of the frame is predicted by calculating cumulative damage. The results of the former are conservative, while the latter are less accurate because the stress spectrum is difficult to deal with [9]. In view of the above reasons, static method is usually used in the design stage to check the fatigue strength of the frame and the accuracy of calculation is verified by comparison of experimental and simulation results, so as to provide guidance for the design. Currently, there are many reports about fatigue strength analysis of bogie frame at home and abroad. Kim [10] proposed a method of evaluating bogie frame fatigue strength based on GSFLD, which combines multi-body dynamics with structural strength simulation and verified the accuracy of the evaluation through experiments. Different from Kim's assessment method, Wang et al [11] obtains the equivalent stress of key parts of the frame through simulation calculation and line measurement, and evaluates the static strength and fatigue strength according to JIS E 4207 standard. Although the methods of the two scholars are different, they are all based on the nominal stress method for fatigue strength assessment. In order to obtain more accurate calculation results, Wang et al [12] employed hot spot stress method to analyze fatigue strength of bogie welded frame. However, the Wang's method can only be applied to evaluate the welded joints with stress perpendicular to the toe and fatigue crack initiation at the toe. It can't be applied to evaluate the welded joints with fatigue cracks at the weld root and continuous welds subjected to longitudinal loads. Compared with the above methods, Lu et al [13] enhanced the efficiency of structural fatigue strength analysis by comparing the results of finite element analysis of fatigue strength of two different models.

The above studies all take the deterministic model as the research object, without considering the uncertainty of design parameters in the process of machining and manufacturing. The results of fatigue strength assessment based on safety factor are conservative, which is not conducive to lightweight design of bogie frame. Therefore, to further reduce the redundancy of fatigue strength analysis of bogie frame, this study modifies traditional approach. In the process of establishing finite element model, the uncertainty of design variables is taken into account. The response surface function of mean stress and stress amplitude are established, and the control points in consideration of uncertainty parameters are calculated. Based on this, the expression of GSFLD function without considering safety factor is derived, and the fatigue strength reliability of control point is calculated with reliability theory.

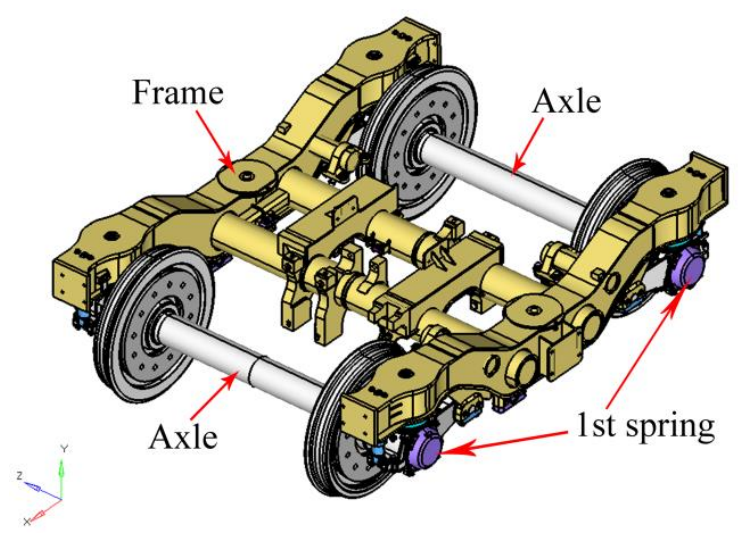

(a) Geometric model of bogie frame

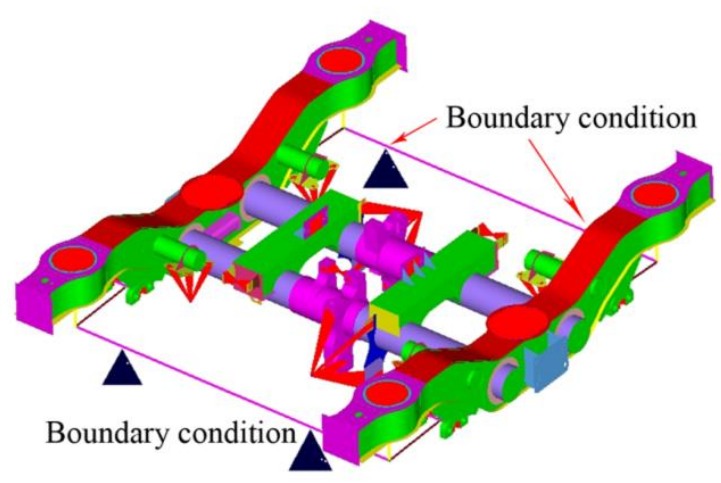

(b) Finite element model of bogie frame

Figure 1: Geometric model and finite element model of bogie frame 


\section{FATIGUE STRENGTH ANALYSIS OF BOGIE FRAME BASED ON DETERMINISTIC MODEL}

\section{FE model of the bogie frame}

$\mathrm{I}$ $\mathrm{n}$ this paper, the analyzed bogie is a metro bogie (Fig. 1(a)). The numerical analysis by the FEM is performed to evaluate the fatigue strength of the bogie frame. A study conducted by Lu shows that the calculation results of the shell model without considering weld details are more conservative than those of the shell model considering weld details. It is feasible to adopt the conservative method of seamless structure modeling in engineering design. [14]. Therefore, the bogie which is modeled by shell and solid model, is given in Fig. 1(b). The bogie frame is modeled using beam188, COMBIN14, shell181 and solid185 elements. It is meshed to have 730,423 elements, including 123,755 triangular and quadrilateral shell elements and 606,659 tetrahedral and hexahedral solid elements. Considering the boundary conditions of the bogie frame for the primary suspension, the spring elements COMBIN14 are established and the stiffness of the elements is the same as the primary suspension. The material of the bogie frame is $\mathrm{S} 355 \mathrm{~J} 2(\mathrm{H})$ and Q345D (yield strength $=355 \mathrm{MPa}$ and $355 \mathrm{MPa}$ ).

\section{Definition of the load conditions}

In conventional load cases, fatigue strength analysis is performed based on the UIC standard. The main in-service load case is designed to verify the absence of any risk of fatigue cracks that could occur under the combined effect of the main forces encountered during service. Therefore, in this study, six fatigue conditions are calculated according to UIC615-4 and EN13749 standard. Tab. 1 and Tab. 2 show the fatigue conditions for each load. The twisting loads of 1 and 2 working conditions are $11 \mathrm{~mm}, 3$ and 4 working conditions are $-11 \mathrm{~mm}$.

\begin{tabular}{|c|c|c|c|c|c|c|c|}
\hline $\begin{array}{l}\text { Load } \\
\text { case }\end{array}$ & $\begin{array}{c}\text { Air spring } \\
\text { vertical and } \\
\text { right }\end{array}$ & $\begin{array}{c}\text { Air spring } \\
\text { vertical and } \\
\text { left }\end{array}$ & $\begin{array}{l}\text { Air spring } \\
\text { horizontal }\end{array}$ & $\begin{array}{c}\text { Lateral } \\
\text { stop }\end{array}$ & Longitudinal & $\begin{array}{c}\text { Gear box } \\
\text { hanger } \\
\text { Front/After }\end{array}$ & $\begin{array}{c}\text { Braking } \\
\text { Front/After }\end{array}$ \\
\hline 1 & 107.5 & 83.4 & 16.1 & 62.6 & 52.3 & $-23.8 / 23.8$ & $-8.8 / 8.8$ \\
\hline 2 & 155 & 131.1 & 16.1 & 62.6 & 52.3 & $-23.8 / 23.8$ & $-8.8 / 8.8$ \\
\hline 3 & 83.4 & 107.3 & -16.1 & -62.6 & -52.3 & $23.8 /-23.8$ & $8.8 /-8.8$ \\
\hline 4 & 131.2 & 155 & -16.1 & -62.6 & -52.3 & $23.8 /-23.8$ & $8.8 /-8.8$ \\
\hline
\end{tabular}

Table 1: Load cases for operational loads $(\mathrm{kN})$

\begin{tabular}{cccccccccc}
\hline $\begin{array}{c}\text { Load } \\
\text { case }\end{array}$ & $\begin{array}{c}\text { Air spring } \\
\text { vertical and } \\
\text { right }\end{array}$ & $\begin{array}{c}\text { Air spring } \\
\text { vertical and } \\
\text { left }\end{array}$ & $\begin{array}{c}\text { Vertical } \\
\text { inertia of } \\
\text { motor }\end{array}$ & $\begin{array}{c}\text { Transverse } \\
\text { inertia of } \\
\text { motor }\end{array}$ & $\begin{array}{c}\text { Longitudinal } \\
\text { inertia of } \\
\text { motor }\end{array}$ & $\begin{array}{c}\text { Gear box } \\
\text { hanger } \\
\text { front/after }\end{array}$ & $\begin{array}{c}\text { Vertical } \\
\text { inertia of } \\
\text { brake }\end{array}$ & $\begin{array}{c}\text { Transverse } \\
\text { inertia of } \\
\text { brake }\end{array}$ & $\begin{array}{c}\text { Longitudinal } \\
\text { inertia of } \\
\text { brake }\end{array}$ \\
5 & 119.3 & 119.3 & -20.8 & -20.8 & -20.8 & $-5.2 /-5.2$ & -3.9 & -3.9 & -3.9 \\
6 & 119.3 & 119.3 & 31.2 & 20.8 & 20.8 & $7.8 / 7.8$ & 5.9 & 3.9 & 3.9 \\
\hline
\end{tabular}

Table 2: Load cases for inertial load $(\mathrm{kN})$

Tab. 3 shows the mechanical properties of the materials used in the bogie frame. The material of steel plate and primary spring seat is $\mathrm{S} 355 \mathrm{~J} 2(\mathrm{H})$ and the cross beam and traction seat are made from Q345D.

\begin{tabular}{cccccc}
\hline & Type & $\begin{array}{c}\text { Material } \\
\text { type }\end{array}$ & $\begin{array}{c}\text { Yielding } \\
\text { strength }\end{array}$ & $\begin{array}{c}\mathrm{S}=1 \\
\text { Yielding } \\
\text { strength }\end{array}$ & $\begin{array}{c}\mathrm{S}=1.1 \\
\text { Yielding } \\
\text { strength }\end{array}$ \\
$\begin{array}{c}\text { Bogie } \\
\text { frame }\end{array}$ & $\begin{array}{c}\text { Steel plate } \\
\text { Primary spring seat } \\
\text { Cross beam } \\
\text { Traction seat }\end{array}$ & S355J2(H) & $355(\leqslant 16 \mathrm{~mm})$ & 355 & 322 \\
& Q345D & $345(>16 \mathrm{~mm})$ & 345 & 313 \\
\hline
\end{tabular}

Table 3: Material properties of the bogie frame (MPa) 
Fatigue strength analysis of bogie frame

The equivalent stress occurring in the bogie frame on exceptional loads should be less than the yield strength of the used material and $\mathrm{S}=1.1$ should be retained in the weld. Under the normal service loads, the mean stress and stress amplitude are calculated on each load and they should be within the fatigue limit diagram. However, the bogie frame of railway vehicle bears vertical, transverse, longitudinal and oblique symmetrical loads during its service, which belongs to the typical multi-axle load state. For this purpose, this paper calculates the stress and amplitude according to the multi-axial stress state-uniaxial stress state transition method provided by ORE B12/RP17.
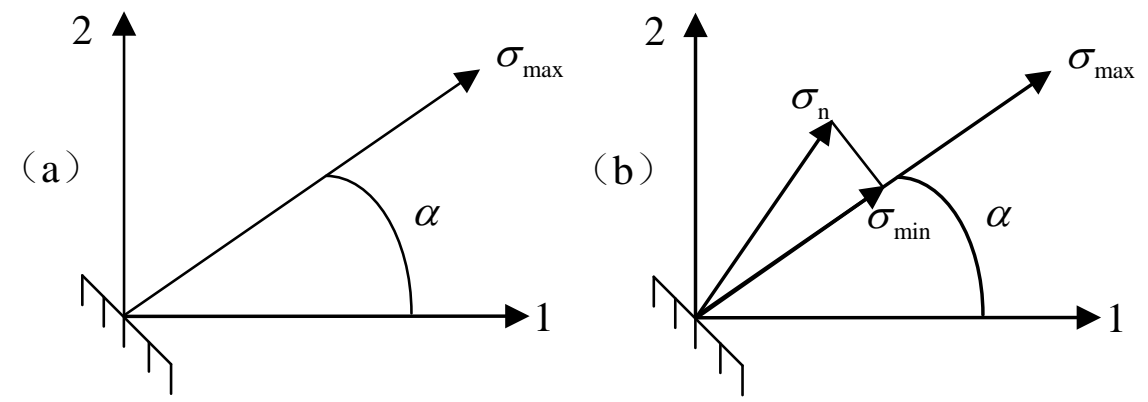

Figure 2: Determination of maximum and minimum principal stresses

The maximum principal stress direction of the structure under all load conditions is taken as the basic stress distribution direction, and its value is calculated as the maximum principal stress $\sigma_{\max }$, as shown in Fig. 2(a). The principal stress under other loading conditions is projected to the determined direction of maximum principal stress, and the minimum principal stress is determined as the minimum principal stress $\sigma_{\min }$, as shown in Fig. 2(b). By calculating the mean stress $\sigma_{\mathrm{m}}$ and stress amplitude $\sigma_{a}$ or stress ratio $\mathrm{R}$ from the maximum and minimum principal stress values, the transformation from multi-axial stress state to uniaxial stress state is completed. The mean stress $\sigma_{\mathrm{m}}$ and the stress amplitude $\sigma_{a}$ are defined as follows

$$
\sigma_{m}=\frac{\sigma_{\max }+\sigma_{\min }}{2} \quad \sigma_{a}=\frac{\sigma_{\max }-\sigma_{\min }}{2}
$$

According to Tab. 1 and Tab. 2, finite element analysis of bogie frame is conducted. Fig. 3 displays the maximum utilization rate of all welds under fatigue conditions. The mean stress and stress amplitude are calculated under fatigue conditions, and the results of evaluating the fatigue limit diagram is obtained, as detailed in Fig 4.

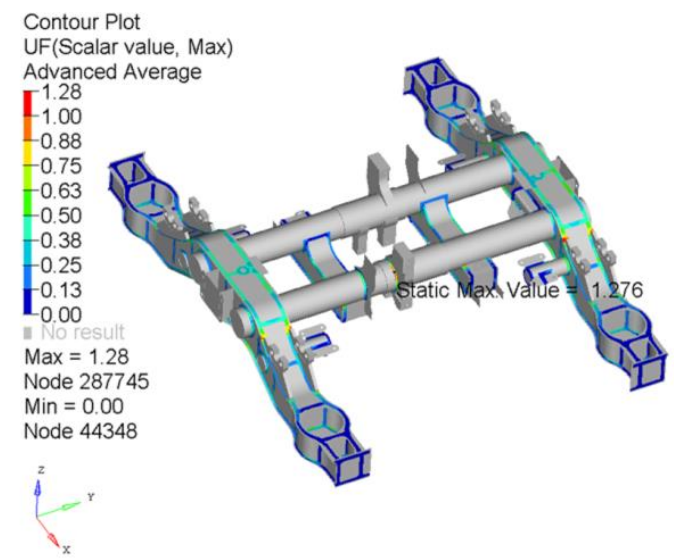

Figure 3: Maximum utilization rate plot of fatigue conditions

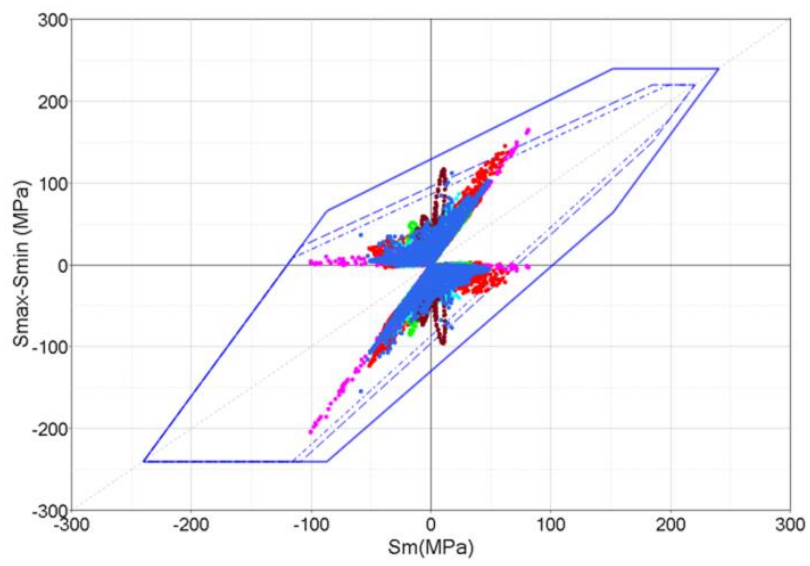

Figure 4: Fatigue analysis results of bogie frame 
It is seen from Fig. 3 that the maximum utilization rate of all welds in the frame is 1.28 , which occurs at the junction of the motor hanger and the cross beam, indicating that the welds in the frame do not meet the standard requirements. Fig. 4 is the corresponding fatigue assessment results based on GSFLD. The GSFLD given in Fig. 4 is a traditional GSFLD, which is a fatigue strength diagram with comprehensive consideration of fatigue stress amplitude, average stress and mechanical property limitation of materials. It is often used in the fatigue design of railway vehicle structural components. For example, JIS E4207-1992 (Track frames for railway rolling stock-General rules for design) and UIC ORE B12/RP17 (Tractive units-Bogies and running gear-Bogie frame structure strength tests) all take this diagram as design standard. This diagram is usually understood as "fatigue limit diagram", which mainly includes the GSFLD of the base metal (outermost), butt weld (middle) and other weld (innermost). The corresponding limit values of turning points are shown in Tab. 4. It can be observed from the Fig.4 that some points have exceeded the weld evaluation area. It shows that under traditional GSFLD, the over-standard points do not meet the standard requirements and the frame needs to be optimized.

\begin{tabular}{cccccc}
\hline \multicolumn{2}{c}{ Base metal } & \multicolumn{2}{c}{ Butt welds } & \multicolumn{2}{c}{ Other welds } \\
$\mathrm{x}$ & $\mathrm{y}$ & $\mathrm{x}$ & $\mathrm{y}$ & $\mathrm{x}$ & $\mathrm{y}$ \\
240 & 240 & 220 & 220 & 220 & 220 \\
152 & 240 & 188 & 220 & 200 & 220 \\
-88 & 65 & -110 & 22 & -118 & 8 \\
-240 & -240 & -240 & -240 & -240 & -240 \\
-85 & -240 & -108 & -240 & -116 & -240 \\
152 & 64 & 185 & 150 & 198 & 176 \\
240 & 240 & 220 & 220 & 220 & 220 \\
\hline
\end{tabular}

Table 4: Turning point value of GSFLD of steel with tensile strength greater than $520 \mathrm{MPa}$

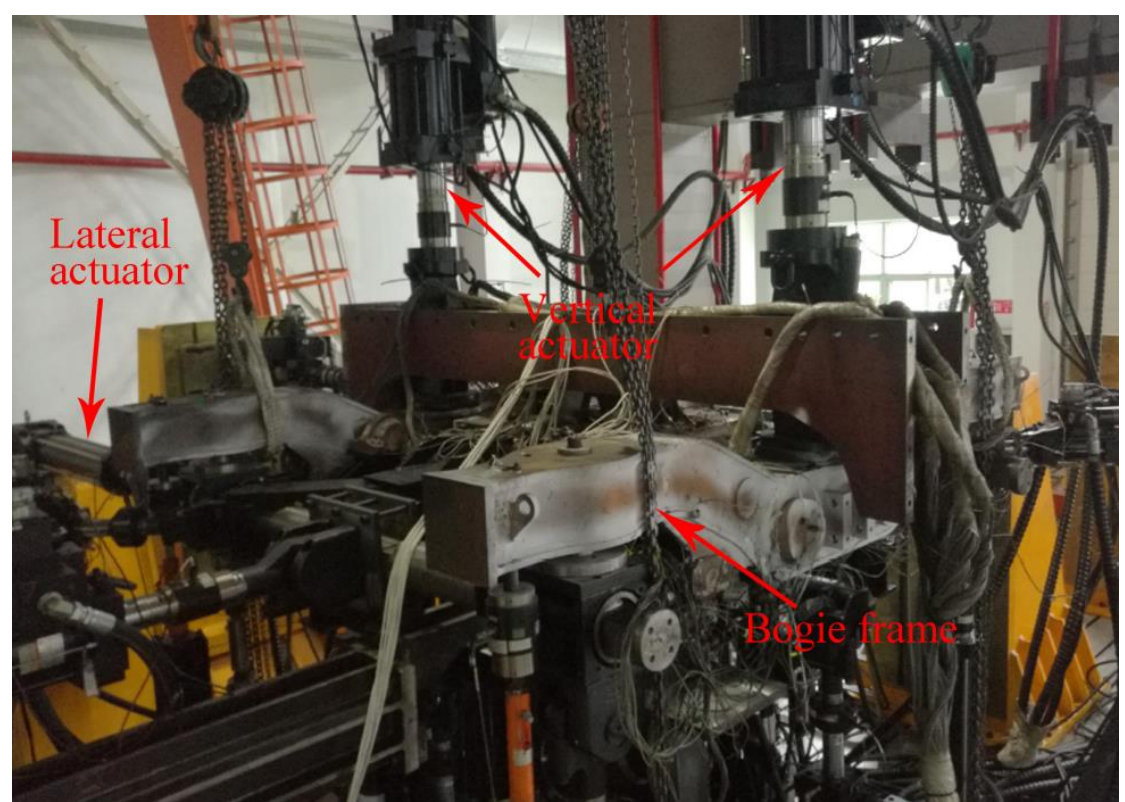

Figure 5: Platform and support mode of fatigue test

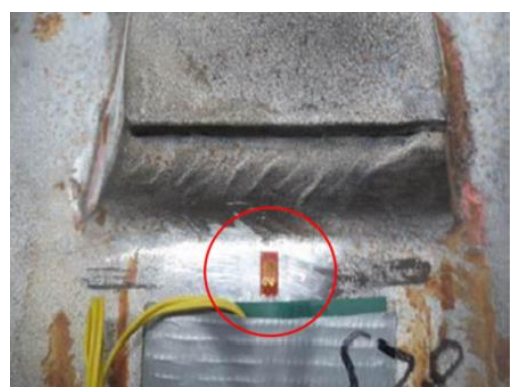

(a) Strain gauge measuring point

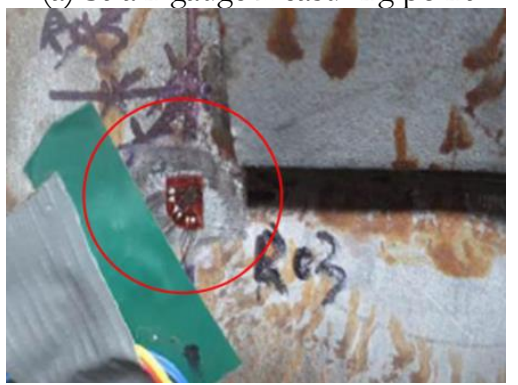

(b) Rosette measuring point Figure 6: Frame measuring point

\section{Experimental verification}

The object of fatigue test that is performed based on the fatigue conditions specified in Tab. 1 and Tab. 2. It is to verify the fatigue strength of bogie frame experimentally and to study the reliability of the fatigue analysis results. Fatigue test is carried out on the ZJZ (JP) 144 MTS multi-channel fatigue test bed. The test loads are applied and distributed by the test tooling to the exact locations where these forces are generated in actual operation. The loading frequency is $5 \mathrm{~Hz}$, and the loading waveform refers to UIC 615-4-2003 standard, which mainly includes the following three stages: (1) vertical and transverse loads $6 \times 10^{6}$ cycles, twisted loads $6 \times 10^{6}$ cycles; (2) vertical and transverse loads $2 \times 10^{6}$ cycles, static load remains unchanged, quasi-static and dynamic loads are multiplied by 1.2. Twist load is multiplied by 1.2 and cycle $0.2 \times 10^{6}$ times; (3) vertical and transverse loads cycles $2 \times 10^{6}$ times while static load remains unchanged. Quasi-static and 
dynamic loads are multiplied by 1.4 and cycle $0.2 \times 10^{6}$ times. The equipment and specimen for fatigue test are shown in Fig. 5. Fig. 6 describes the strain gauge type at the welding of bogie frame.

\begin{tabular}{cccccc}
\hline \multicolumn{2}{c}{ Base metal } & \multicolumn{2}{c}{ Butt welds } & \multicolumn{2}{c}{ Other welds } \\
$\mathrm{x}$ & $\mathrm{y}$ & $\mathrm{x}$ & $\mathrm{y}$ & $\mathrm{x}$ & $\mathrm{y}$ \\
170 & 170 & 155 & 155 & 155 & 155 \\
84 & 170 & 88 & 155 & 101 & 155 \\
-50 & 78 & -58 & 60 & -66 & 45 \\
-170 & -170 & -170 & -170 & -170 & -170 \\
-50 & -170 & -58 & -170 & -66 & -170 \\
84 & -2 & 88 & 21 & 101 & 47 \\
170 & 170 & 155 & 155 & 155 & 155 \\
\hline
\end{tabular}

Table 5: Turning point value of GSFLD of steel with tensile strength greater than 420MPa

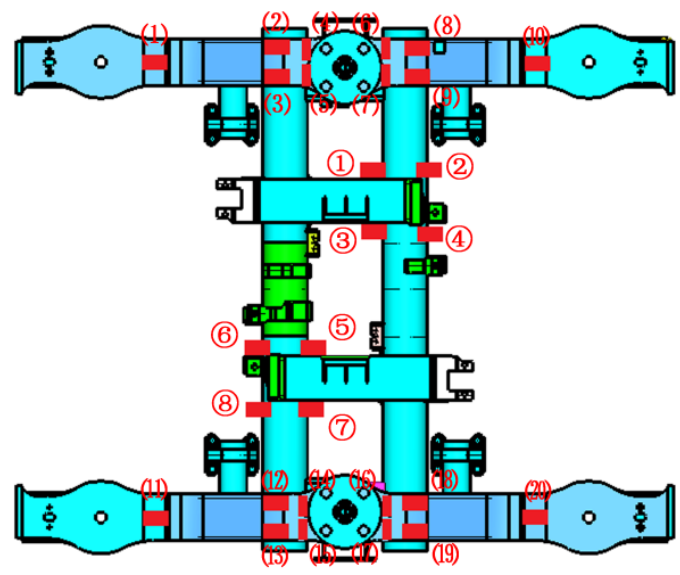

Figure 7: Schematic diagram of bogie frame patch layout

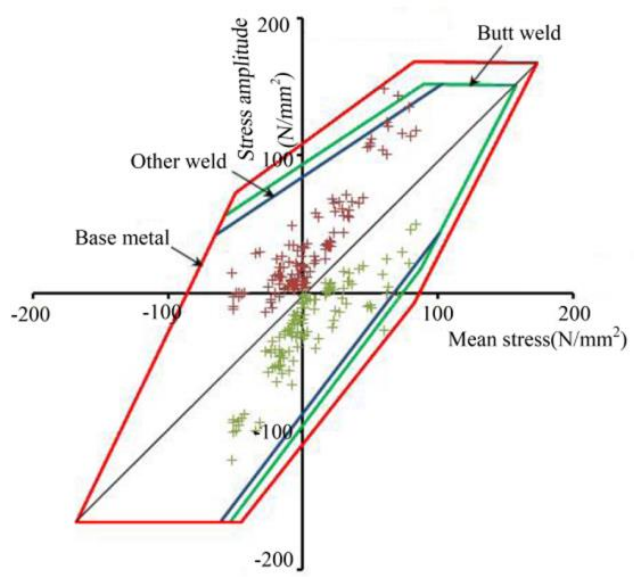

Figure 8: Fatigue analysis results of bogie frame

Fig. 7 presents part of the strain gauge position of the bogie frame. It can be seen that the location of the patch is mostly the weld, which indicates that the evaluation of fatigue strength of the weld is more important. Then, compared with the position of the weld shown in Fig. 3, there are fewer test points in the experiment, which can't reflect the fatigue situation of all welds. Hence, the combination of finite element simulation and experiment can more accurately evaluate the fatigue strength of the bogie frame. Figure 8 displays the fatigue strength analysis results of the frame based on GSFLD of ORE B12/RP17. The GSFLD given in Fig. 8 are basically similar to those in Fig. 4, which include GSFLD of base metal, butt weld and other weld. The difference is that the limit values of the turning points of GSFLD in Fig. 4 are based on steel with tensile strength greater than $520 \mathrm{MPa}$, while those in Fig. 8 are based on steel with tensile strength greater than $420 \mathrm{MPa}$. However, because the maximum yield strength of bogie frame is 355 $\mathrm{MPa}$, which is less than the steel used in GSFLD, Therefore, both types of GSFLD can be used as standard to judge whether the fatigue strength of the frame meets the requirements. In order to increase the evaluation range of fatigue strength, the GSFLD of steel with tensile strength greater than $520 \mathrm{MP}$ is generally selected in the actual simulation analysis Tab. 5 shows the limit value of the turning point corresponding to the GSFLD in Fig. 8. It can be seen that the fatigue strength analysis results of each test point are basically in the GSFLD of the weld, which meets the standard requirements. However, some of the test points are beyond or near the GSFLD, which is more dangerous to the fatigue design of the frame. As can be seen from the comparison between Fig. 4 and Fig. 5, the results of experiment and simulation are basically the same. Since the simulation calculation has continuity in extracting the fatigue strength analysis results of welds, there are more over-standard points. It can be seen that it is feasible to analyze the fatigue strength of bogie frame with simulation analysis in the design stage, and the calculation results are more accurate and reasonable. It can provide some guidance for the anti-fatigue design of bogie frame in detail design stage. 


\section{FATIGUE STRENGTH ANALYSIS OF BOGIE FRAME IN CONSIDERATION OF PARAMETERS UNCERTAINTY}

\section{Establishment of polynomial response surface function}

raditional fatigue strength analysis based on deterministic model can't reflect the influence of uncertainty factors such as size and shape on fatigue strength. Therefore, taking the maximum fatigue strength as the control point and analyzing its fluctuation under the influence of uncertainty factors can effectively characterize the fatigue strength reliability of the frame and provide a basis for lightweight design. In view of this, this study chooses the parameters which have a large impact on fatigue strength of control point as uncertainty variables, and uses APDL language to establish a parametric finite element model. In order to improve the computational efficiency, the D-optimal experimental design is used to select sample points, and the polynomial response surface surrogate model is adopted to characterize the functional relationship between variables and responses [15-17]. According to the fatigue strength analysis results of Fig. 3 and Fig. 4, the node number 287745 is taken as the control point, and the influence of uncertainties on it is calculated. Tab. 6 and Tab. 7 show the range of variables and the D-optimal experimental design process, respectively.

\begin{tabular}{cccccc}
\hline Design parameters & Sign & Unit & Lower limit & Mean value & Upper limit \\
Cross beam & $t_{1}$ & $\mathrm{~mm}$ & 15 & 16 & 17 \\
Vertical inertia & $F_{1}$ & $\mathrm{kN}$ & -21.84 & -20.8 & -19.76 \\
Transverse inertia & $F_{2}$ & $\mathrm{kN}$ & -21.84 & -20.8 & -19.76 \\
Longitudinal inertia & $F_{3}$ & $\mathrm{kN}$ & -21.84 & -20.8 & -19.76 \\
Vertical inertia & $F_{4}$ & $\mathrm{kN}$ & 29.64 & 31.2 & 32.76 \\
Transverse inertia & $F_{5}$ & $\mathrm{kN}$ & 19.76 & 20.8 & 21.84 \\
Longitudinal inertia & $F_{6}$ & $\mathrm{kN}$ & 19.76 & 20.8 & 21.84 \\
\hline
\end{tabular}

Table 6: Uncertainty design parameters.

\begin{tabular}{cccccccccc}
\hline $\begin{array}{c}\text { Run } \\
\text { number }\end{array}$ & $\hbar_{1}(\mathrm{~mm})$ & $F_{1}(\mathrm{kN})$ & $F_{2}(\mathrm{kN})$ & $F_{3}(\mathrm{kN})$ & $F_{4}(\mathrm{kN})$ & $F_{5}(\mathrm{kN})$ & $F_{6}(\mathrm{kN})$ & $\mathrm{X}$ & $\mathrm{Y}$ \\
1 & 15 & -19.76 & -19.76 & -19.76 & 31.1844 & 21.84 & 19.76 & 12.4326 & 118.454 \\
2 & 15 & -19.76 & -21.7568 & -21.84 & 30.108 & 20.9917 & 21.84 & 14.3174 & 121.604 \\
3 & 15 & -21.84 & -21.84 & -19.76 & 29.64 & 19.76 & 19.76 & 11.2513 & 117.517 \\
$\ldots$ & $\ldots$ & $\ldots$ & $\ldots$ & $\ldots$ & $\ldots$ & $\ldots$ & $\ldots$ & $\ldots$ & $\ldots$ \\
44 & 17 & -19.76 & -21.84 & -19.76 & 29.64 & 19.76 & 19.76 & 7.86325 & 112.135 \\
45 & 17 & -21.84 & -19.76 & -21.84 & 29.64 & 19.76 & 21.84 & 8.02718 & 113.298 \\
46 & 17 & -21.84 & -21.84 & -19.76 & 29.64 & 19.76 & 21.84 & 6.61196 & 113.293 \\
\hline
\end{tabular}

Table 7: D-optimal experimental design and response value.

The polynomial response function with cross-terms is obtained by fitting the sample points obtained by experiment design with the least square method and the basic equation is given by

$$
y=\sum_{i=1}^{n} c_{i i} x_{i}^{2}+\sum_{i>j}^{n} c_{i j} x_{i} x_{j}+\sum_{i=1}^{n} c_{i} x_{i}+c_{0}
$$

where $n$ is the number of uncertain variables, $c_{0}$ is the constant, and $c_{i}, c_{i i}$, and $c_{i j}$ are the polynomial coefficients, respectively.

According to Eqn. (2), the experimental data in Tab. 7 are fitted to obtain the response surface function of the control point coordinates, in which $\mathrm{X}$ represents the mean stress and $\mathrm{Y}$ represents the stress amplitude. 


$$
\begin{aligned}
& X=+5.272+0.267 \times t_{1}+0.844 \times F_{1}+0.958 \times F_{2}+0.184 \times F_{3}+0.536 \times F_{4}+1.131 \times F_{5}-0.129 \times F_{6} \\
& +2.828 \times 10^{-3} \times t_{1} \times F_{1}+6.505 \times 10^{-3} \times t_{1} \times F_{2}+4.691 \times 10^{-3} \times t_{1} \times F_{3}+4.041 \times 10^{-3} \times t_{1} \times F_{4}+3.900 \times 10^{-3} \\
& \times t_{1} \times F_{5}+3.205 \times 10^{-3} \times t_{1} \times F_{6}+1.383 \times 10^{-3} \times F_{1} \times F_{2}+1.838 \times 10^{-3} \times F_{1} \times F_{3}+3.826 \times 10^{-4} \times F_{1} \times F_{4} \\
& -1.659 \times 10^{-3} \times F_{1} \times F_{5}+8.623 \times 10^{-4} \times F_{1} \times F_{6}+1.752 \times 10^{-4} \times F_{2} \times F_{3}+2.331 \times 10^{-4} \times F_{2} \times F_{4}-1.265 \times 10^{-4} \\
& \times F_{2} \times F_{5}-1.067 \times 10^{-3} \times F_{2} \times F_{6}+6.201 \times 10^{-4} \times F_{3} \times F_{4}+1.710 \times 10^{-3} \times F_{3} \times F_{5}-2.139 \times 10^{-4} \times F_{3} \times F_{6} \\
& +3.634 \times 10^{-4} \times F_{4} \times F_{5}+7.699 \times 10^{-4} \times F_{4} \times F_{6}-1.938 \times 10^{-3} \times F_{5} \times F_{6}-6.660 \times 10^{-3} \times t_{1}^{2}-1.367 \times 10^{-3} \\
& \times F_{1}^{2}+1.380 \times 10^{-3} \times F_{2}^{2}-2.712 \times 10^{-4} \times F_{3}^{2}+4.437 \times 10^{-3} \times F_{4}^{2}-5.182 \times 10^{-3} \times F_{5}^{2}+8.601 \times 10^{-3} \times F_{6}^{2} \\
& Y=+66.695+4.045 \times t_{1}+0.118 \times F_{1}+1.758 \times F_{2}-0.617 \times F_{3}-2.631 \times F_{4}+5.914 F_{5}-4.453 \times F_{6} \\
& +2.828 \times 10^{-3} \times t_{1} \times F_{1}+6.505 \times 10^{-3} \times t_{1} \times F_{2}+4.691 \times 10^{-3} \times t_{1} \times F_{3}+4.041 \times 10^{-3} \times t_{1} \times F_{4}+3.900 \\
& \times 10^{-3} \times t_{1} \times F_{5}+3.205 \times 10^{-3} \times t_{1} \times F_{6}+1.383 \times 10^{-3} \times F_{1} \times F_{2}+1.838 \times 10^{-3} \times F_{1} \times F_{3}+3.826 \times 10^{-4} \\
& \times F_{1} \times F_{4}-1.659 \times 10^{-3} \times F_{1} \times F_{5}+8.623 \times 10^{-4} \times F_{1} \times F_{6}+1.752 \times 10^{-4} \times F_{2} \times F_{3}+2.331 \times 10^{-4} \times F_{2} \\
& \times F_{4}-1.265 \times 10^{-4} \times F_{2} \times F_{5}-1.067 \times 10^{-3} \times F_{2} \times F_{6}+6.201 \times 10^{-4} \times F_{3} \times F_{4}+1.710 \times 10^{-3} \times F_{3} \times F_{5} \\
& -2.139 \times 10^{-4} \times F_{3} \times F_{6}+3.634 \times 10^{-4} \times F_{4} \times F_{5}+7.699 \times 10^{-4} \times F_{4} \times F_{6}-1.938 \times 10^{-3} \times F_{5} \times F_{6} \\
& -6.660 \times 10^{-3} \times t_{1}^{2}-1.367 \times 10^{-3} \times F_{1}^{2}+1.380 \times 10^{-3} \times F_{2}^{2}-2.712 \times 10^{-4} \times F_{3}^{2}+4.437 \times 10^{-3} \times F_{4}^{2} \\
& -5.182 \times 10^{-3} \times F_{5}^{2}+8.601 \times 10^{-3} \times F_{6}^{2}
\end{aligned}
$$

The accuracy of response surface is the basis for ensuring the validity of experimental design and response surface function, and the premise of further analysis by using this model. The accuracy of response surface function and the significance of choosing design parameters can be obtained by checking the accuracy of response surface function, which is helpful to determine whether the selected design parameters are reasonable or not. In this paper, ANOVA is used to analyze the model. Some results are shown in Tab. 8 and Tab. 9. In order to better observe the fitting accuracy of response surface, the correlation diagrams of experimental and predicted values are given in Fig. 9, in which actual represents the results of finite element calculation and predicted represents the results of response surface calculation.

The $\mathrm{F}$ and $\mathrm{P}$ values in the table represent the significance of correlation coefficients. The larger of the $\mathrm{F}$ value, the more significant of the correlation coefficients is. On the contrary, the smaller of the $\mathrm{P}$ value, the more significant of the correlation coefficient is. As can be seen from Tab. 8, the response surface model is significant, and the sensitivity of each design parameter to the response is significant, as well. It shows that the fitting accuracy of response surface is high and the selection of design parameters is reasonable. Because of space, the interaction among design parameters can't be given. Through analysis, it is found that the interaction among design parameters in response surface function is relatively low, which indicates that the interaction between design parameters has less influence on response. Similarly, Tab. 9 shows that although the sensitivity of each design parameter to response is not all significant, the response surface model is generally significant. Combining Tab. 8 and Tab. 9, we can see that although the significance of design parameters to $\mathrm{X}$ and $\mathrm{Y}$ is different, the control points $(\mathrm{X}, \mathrm{Y})$ composed of $\mathrm{X}$ and $\mathrm{Y}$ still show significant characteristics, which indicates that the selected design variables have a greater impact on the control points, and further proves the rationality of the selection of design variables. It can be observed from Fig. 9 that all design points are near the $45^{\circ}$ diagonal line, and the residual is small, which shows that the predicted values of response surface functions $\mathrm{X}$ and $\mathrm{Y}$ are quite close to the actual values.

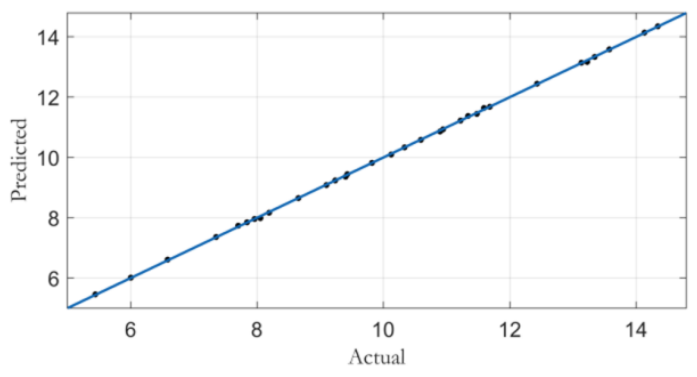

(a) Fitting accuracy of response surface $\mathrm{X}$

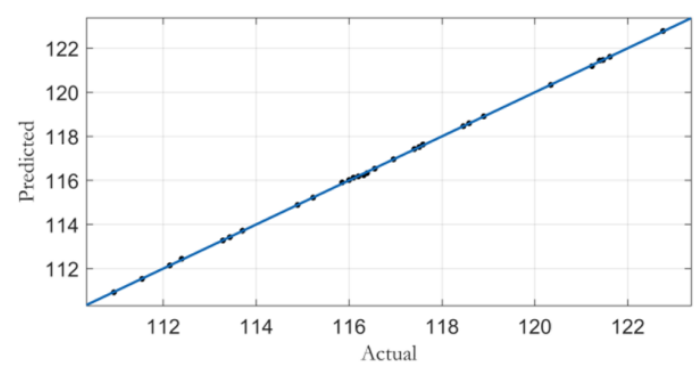

(b) Fitting accuracy of response surface Y

Figure 9: Fitting accuracy of control points 


\begin{tabular}{ccccccl}
\hline $\begin{array}{c}\text { Source } \\
\text { model }\end{array}$ & $\begin{array}{c}\text { Sum of } \\
\text { Squares }\end{array}$ & Df & $\begin{array}{c}\text { Mean } \\
\text { Square }\end{array}$ & $\begin{array}{c}F \\
\text { Value }\end{array}$ & $\begin{array}{c}\text { P-value } \\
\text { Prob }>F\end{array}$ & \\
Model & 230.04 & 35 & 6.57 & $6.873 \mathrm{E}+5$ & $<0.0001$ & significant \\
$t_{1}$ & 0.036 & 1 & 0.036 & 3735.32 & $<0.0001$ & significant \\
$F_{1}$ & 17.85 & 1 & 17.85 & $1.867 \mathrm{E}+6$ & $<0.0001$ & significant \\
$F_{2}$ & 26.41 & 1 & 26.41 & $2.762 \mathrm{E}+5$ & $<0.0001$ & significant \\
$F_{3}$ & 1.91 & 1 & 1.91 & $2.0 \mathrm{E}+5$ & $<0.0001$ & significant \\
$F_{4}$ & 51.34 & 1 & 51.34 & $5.369 \mathrm{E}+6$ & $<0.0001$ & significant \\
$F_{5}$ & 24.41 & 1 & 24.41 & $2.552 \mathrm{E}+6$ & $<0.0001$ & significant \\
$F_{6}$ & 2.37 & 1 & 2.37 & $2.48 \mathrm{E}+5$ & $<0.0001$ & significant \\
$\ldots$ & $\ldots$ & $\ldots$ & $\ldots$ & $\ldots$ & $\ldots$ & $\ldots$ \\
Residual & $9.562 \mathrm{E}-5$ & 10 & $9.562 \mathrm{E}-5$ & & & \\
Lack of Fit & $9.562 \mathrm{E}-5$ & 5 & $1.912 \mathrm{E}-5$ & $1.125 \mathrm{E} 6+5$ & $<0.0001$ & significant \\
Pure Error & $8.500 \mathrm{E}-10$ & 5 & $1.700 \mathrm{E}-10$ & & & \\
Cor Total & 230.04 & 45 & & & & \\
\hline
\end{tabular}

Table 8: ANOVA for response surface X quadratic model.

\begin{tabular}{ccccccc}
\hline $\begin{array}{c}\text { Source } \\
\text { model }\end{array}$ & $\begin{array}{c}\text { Sum of } \\
\text { Squares }\end{array}$ & Df & $\begin{array}{c}\text { Mean } \\
\text { Square }\end{array}$ & $\begin{array}{c}F \\
\text { Value }\end{array}$ & $\begin{array}{c}\text { P-value } \\
\text { Prob }>F\end{array}$ & \\
Model & 498.34 & 35 & 14.24 & 9191.84 & $<0.0001$ & significant \\
$t_{1}$ & 9.08 & 1 & 9.08 & 5860.00 & $<0.0001$ & significant \\
$F_{1}$ & $1.326 \mathrm{E}-3$ & 1 & $1.326 \mathrm{E}-3$ & 0.86 & 0.3766 & non-significant \\
$F_{2}$ & 0.026 & 1 & 0.026 & 16.82 & 0.0021 & non-significant \\
$F_{3}$ & 0.041 & 1 & 0.041 & 26.19 & 0.0005 & non-significant \\
$F_{4}$ & 206.54 & 1 & 206.54 & $1.33 \mathrm{E}+5$ & $<0.0001$ & significant \\
$F_{5}$ & 94.29 & 1 & 94.29 & 60871.61 & $<0.0001$ & significant \\
$F_{6}$ & 9.65 & 1 & 9.65 & 6229.75 & $<0.0001$ & significant \\
$\ldots$ & $\ldots$ & $\ldots$ & $\ldots$ & $\ldots$ & $\ldots$ & $\ldots$ \\
Residual & 0.015 & 10 & $1.549 \mathrm{E}-5$ & & & \\
Lack of Fit & 0.015 & 5 & $3.098 \mathrm{E}-3$ & & & \\
Pure Error & 0.000 & 5 & 0.000 & & & \\
Cor Total & 498.36 & 45 & & & & \\
\hline
\end{tabular}

Table 9: ANOVA for response surface Y quadratic model

The control points value in consideration of parameter uncertainty

In order to calculate the mean stress and stress amplitude of control points more accurately, this study uses the important sampling method to select the sample points of uncertainty parameters. Important sampling method is one of the most effective Monte Carlo techniques, the basic principle is that it doesn't from a given probability distribution function of sampling, but modifies the given probability distribution so as to shift the sampling center towards the failure region to gain information more efficiently [18]. Probability of structural failure can be expressed in the following form

$$
P_{f}=\int_{-\infty}^{+\infty} \frac{I\left[g_{X}(v)\right] f_{X}(v)}{p_{V}(v)} p_{V}(v) d v=E\left\{\frac{I\left[g_{X}(v)\right] f_{X}(v)}{p_{V}(v)}\right\}
$$


where $v$ denotes basic input variables, $g(v)$ is the performance function, $f_{X}(v)$ is the joint probability density function of a random variables, $p_{V}(v)$ is the assumed importance sampling density(ISD).

Obviously, the success of importance sampling relies on the proper choice of ISD. The optimal ISD can be drawn through theoretical analysis [19].

$$
p_{o p t}(v)=\frac{I\left[g_{X}(v)\right] f_{X}(v)}{P_{f}}
$$

In order to illustrate the influence of uncertainties in design parameters on control points, 46 experimental design control points are given based on Tab. 7. Comparing Fig. 3 and Fig. 10 it is seen that due to the uncertainty of design parameters, the control points show a large degree of discreteness, which greatly exceeds the evaluation range of fatigue limit of bogie frame. Fig. 11 plots the distribution of control points based on importance sampling method. It can be clearly seen from the figure that the fluctuation of design parameters leads to a greater dispersion of control points. Comparing Fig. 10 and Fig. 11 shows that the distribution of the control points in the dense area is reasonable, which can reflect the influence of the fluctuation of the over-standard points near the fatigue limit diagram on the fatigue strength analysis results well. Compared with the deterministic model, the results of uncertainty analysis are more in line with engineering practice.

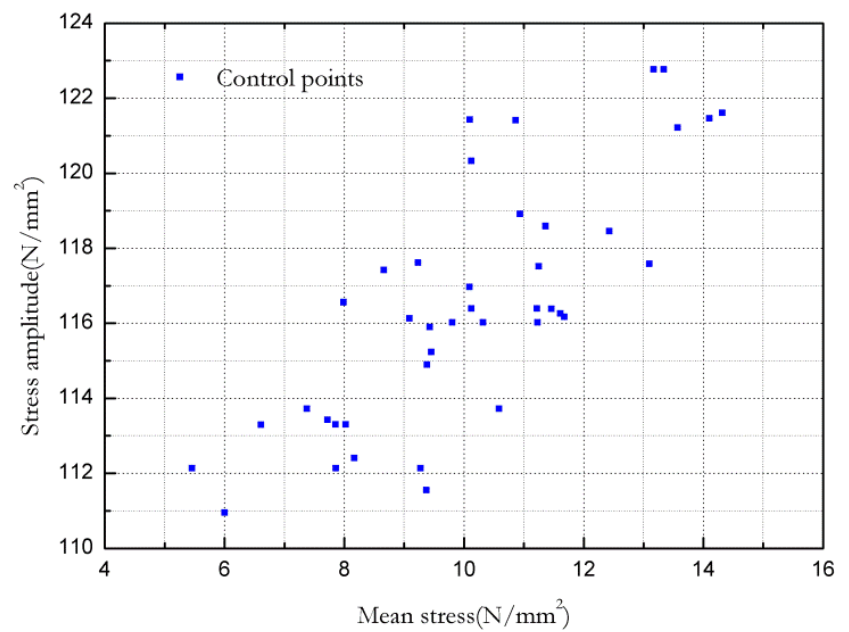

Figure 10: The fluctuation of control points under uncertain factors

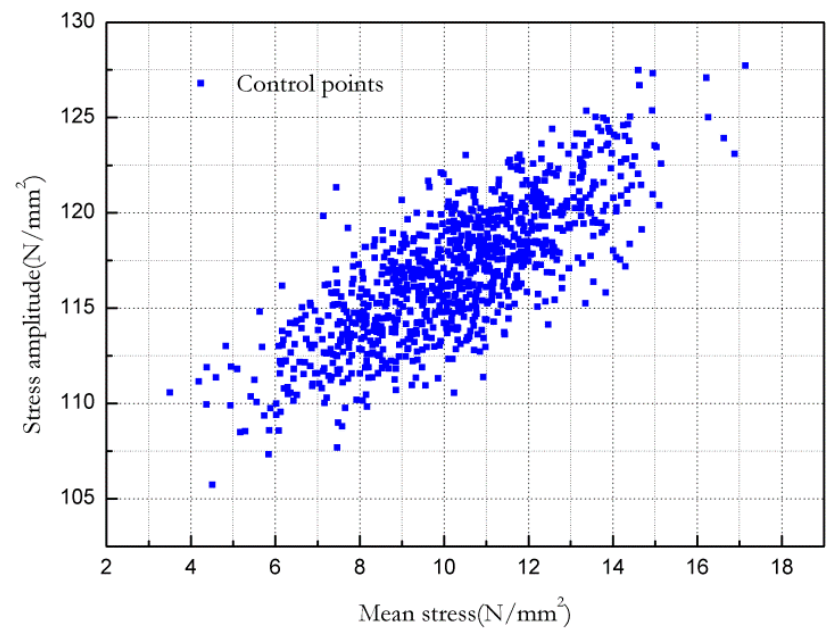

Figure 11: Importance sampling results of control points

\section{Functional expression of Goodman-Smith fatigue limit diagram}

GSFLD is widely used in fatigue strength checking of materials in the world. At present, most railway rolling stock adopt modified GSFLD to design fatigue strength of its parts. The modified Goodman curves are generally divided into two forms: Haigh graphics and Smith graphics. In this paper, the modified GSFLD is used to evaluate the fatigue strength of the frame [20]. The determination of the modified GSFLD requires three limit values, i.e. strength limit $\sigma_{b}$ and yield limit $\sigma_{y t}$ of materials and fatigue limit $\sigma_{-1 N}$ of frame. According to Tab. 3, the yield strength of the material is $345 \mathrm{MPa}$. The ultimate strength of $\mathrm{S} 355 \mathrm{~J} 2(\mathrm{H})$ material is $520 \mathrm{MPa}$. In the traditional GSFLD, when calculating the fatigue limit $\sigma_{-1 N}$ of frame, factors such as size, shape and surface machining quality are involved in the calculation in the form of safety factor.

$$
\begin{aligned}
& \sigma_{-1 N}=\frac{\beta_{-1} \varepsilon}{k_{f}} \sigma_{-1} \\
& \sigma_{-1}=38+0.43 \sigma_{b}
\end{aligned}
$$

where $\beta_{-1}$ is the surface machining factor, $\varepsilon$ is the size factor, $k_{f}$ is the stress concentration factor.

As can be seen from Eqn. (7), the calculation of fatigue limit $\sigma_{-1 N}$ based on safety factor is too conservative, resulting in high redundancy of fatigue strength, which is not conducive to the lightweight design of the frame. Therefore, GSFLD 
without safety factor is adopted to more accurately evaluate the fatigue strength of the frame. Since the cause of stress concentration factor is complex, it is taken as a fixed value. $k_{f}=1.1$ is selected according to the stress concentration coefficient factors diagram provided by BS7608 standard (Guide to fatigue design and assessment of steel structures) and the S-N curve of steel under different stress concentration factors given in the book of fatigue life prediction of structural. The fatigue limit $\sigma_{-1 \mathrm{~N}}$ of the frame and the fatigue limit $\sigma_{-1}$ of the material are calculated to be 237.8MPa and 261.6MPa, respectively. Tab. 10 shows the turning point coordinates of the GSFLD. In Tab. 10, the closed 8-sided region formed by ABCDEFGHA is a GSFLD, with turning points at each point. Among them, A and E are the symmetrical cyclic fatigue strength under given fatigue life N; C and G are the turning points of the tensile yield limit and the compressive yield limit in transverse and longitudinal coordinates, which are equal for general metal materials. B, F, D and $\mathrm{H}$ are turning points to control the limit state when Goodman correction is carried out considering the average stress. In the coordinates of each point, $\sigma_{-1 N}$ is the symmetrical cyclic fatigue strength under given fatigue life $\mathrm{N} ; \sigma_{b}$ is the ultimate tensile strength; $\sigma_{y t}$ is the yield tensile strength; $\sigma_{y c}$ is the ultimate tensile strength. Combined with Tab. 10 and mechanical properties of the frame material, a new Goodman-Smith fatigue limit diagram (NGSFLD) is obtained, as listed in Fig. 12 and Fig. 13.

\begin{tabular}{|c|c|c|c|c|c|}
\hline $\begin{array}{c}\text { Turning } \\
\text { point }\end{array}$ & $\begin{array}{c}\text { Mean stress } \\
\sigma_{m}\end{array}$ & $\begin{array}{c}\text { Stress amplitude } \\
\sigma_{a}\end{array}$ & $\begin{array}{l}\text { Turning } \\
\text { point }\end{array}$ & $\begin{array}{c}\text { Mean stress } \\
\sigma_{m}\end{array}$ & $\begin{array}{c}\text { Stress amplitude } \\
\sigma_{a}\end{array}$ \\
\hline A & 0 & $\sigma_{-1 N}$ & $\mathrm{E}$ & 0 & $-\sigma_{-1 N}$ \\
\hline B & $\frac{\sigma_{y t}-\sigma_{-1 N}}{\sigma_{b}-\sigma_{-1 N}} \sigma_{b}$ & $\sigma_{y t}$ & $\mathrm{~F}$ & $\sigma_{-1 N}-\sigma_{y c}$ & $-\sigma_{y}$ \\
\hline $\mathrm{C}$ & $\sigma_{y t}$ & $\sigma_{y t}$ & G & $-\sigma_{y c}$ & $-\sigma_{y c}$ \\
\hline $\mathrm{D}$ & $\frac{\sigma_{y t}-\sigma_{-1 N}}{\sigma_{b}-\sigma_{-1 N}} \sigma_{b}$ & $\frac{\left(\sigma_{b}+\sigma_{-1 N}\right) \sigma_{y t}-2 \sigma_{b} \sigma_{-1 N}}{\sigma_{b}-\sigma_{-1 N}}$ & $\mathrm{H}$ & $\sigma_{-1 N}-\sigma_{y c}$ & $2 \sigma_{-1 N}-\sigma_{y c}$ \\
\hline
\end{tabular}

Table 10: Goodman-Smith plot of turning point coordinates

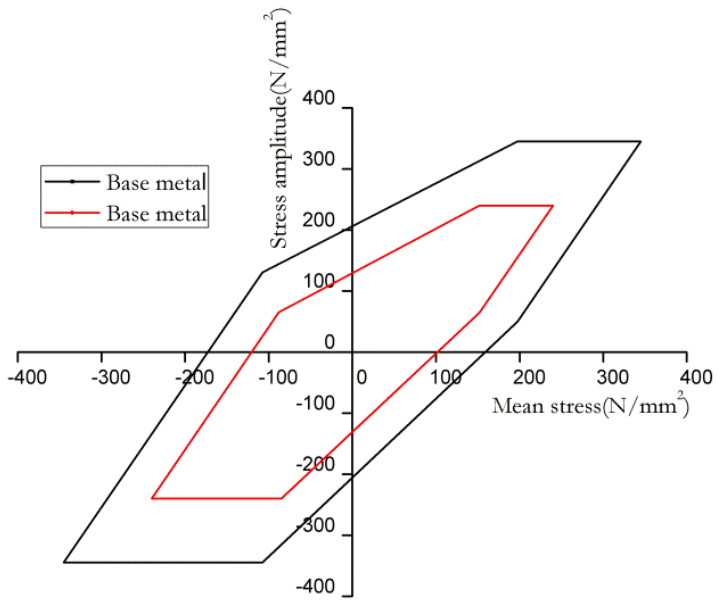

Figure 12: Comparison of Goodman-Smith fatigue limit diagrams

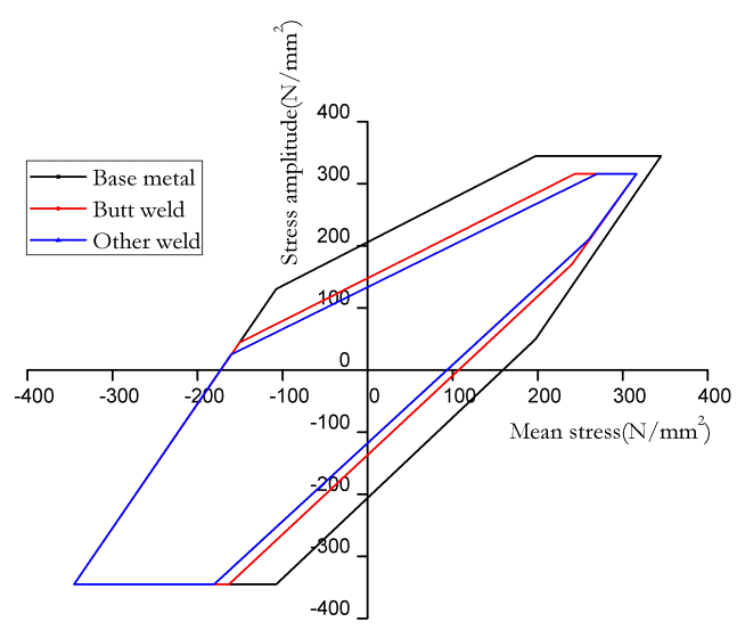

Figure 13: Goodman-Smith fatigue limit diagram without considering the safety factor

The black line in Fig. 12 is GSFLD without safety factors, and the red line is the fatigue limit diagram specified in ORE B12/RP17 standard. Fig. 12 shows that the newly defined GSFLD is broader than the ORE B12/RP17 standard definition, that is, it is more conservative to use the GSFLD defined by ORE B12/RP17 standard to evaluate the fatigue strength of bogie frame. It is not only simple and universal to evaluate the fatigue strength of the frame conservatively in engineering practice, but also to ensure the reliability of the product. However, conservative anti-fatigue design can no longer meet the requirements of rail vehicles which are increasingly pursuing lightweight. Therefore, the redundancy of design can be reduced by using the NGSFLD drawn in Fig. 13 for fatigue strength analysis. Fig. 13 contains the types of 
fatigue strength assessments for base metal, butt weld and other weld forms. In order to evaluate the fatigue strength reliability of the frame, the function expressions of NGSFLD are given in Eqn. (8), Eqn. (9) and Eqn. (10).

$$
\begin{aligned}
& \left\{\begin{array}{cc}
y=345 & (197.5 \leq x \leq 345) \\
y=0.68 x+206 & (-107.2<x<197.5) \\
y=2 x+345 & (-345 \leq x \leq-107.2) \\
y=-345 & (-345 \leq x \leq-107.2) \\
y=1.30 x-206 & (-107.2<x<197.5) \\
y=2.2 x-345 & (197.5 \leq x \leq 345)
\end{array}\right. \\
& \left\{\begin{array}{cc}
y=316.3 & (243.7 \leq x \leq 316.3) \\
y=0.68 x+148 & (-150.5<x<243.7) \\
y=2 x+345 & (-345 \leq x \leq-150.5) \\
y=-345 & (-345 \leq x \leq-150.5) \\
y=1.30 x-148.2 & (-150.5<x<243.7) \\
y=2.2 x-318.9 & (243.7 \leq x \leq 316.3)
\end{array}\right. \\
& \left\{\begin{array}{cc}
y=316.3 & (269.7 \leq x \leq 316.3) \\
y=0.68 x+133.68 & (-160.5<x<269.7) \\
y=2 x+345 & (-345 \leq x \leq-160.5) \\
y=-345 & (-345 \leq x \leq-160.5) \\
y=1.30 x-137.75 & (-160.5<x<269.7) \\
y=2.2 x-401.8 & (269.7 \leq x \leq 316.3)
\end{array}\right.
\end{aligned}
$$

Fatigue strength reliability calculation of control point

Control point as the maximum point of fatigue strength in the deterministic model, its fluctuation under uncertainty variables directly reflects the minimum fatigue strength reliability of the frame. Therefore, the accuracy of fatigue strength reliability analysis of control point provides theoretical support for ensuring the overall fatigue reliability of the frame, reducing design redundancy and lightweight. Traditional fatigue strength analysis of bogie frame is based on observing whether the evaluation points are within the GSFLD or not, and for the evaluation points beyond the NGSFLD, if the stress amplitude does not exceed $20 \%$ of the corresponding yield stress, the fatigue strength design requirements are considered to be satisfied. Because of the excessive security redundancy, this method allows the existence of evaluation points exceeding the standard. However, the excessive safety redundancy makes the bogie frame designed meet the standard requirements, but it is too bulky and does not meet the current goal and demand of lightweight structure. Based on this, the reliability-based fatigue strength analysis method proposed in this paper perfectly solves the above problem. The control points are calculated by Eqn. (3) and (4), and the probability of control points within the fatigue limit diagram is calculated by combining the function expression of GSFLD. The limited state equation of bogie frame can be defined as

$$
Z=Y-f_{X}(x)
$$

The fatigue strength reliability of bogie frame is given by

$$
R=\frac{n}{N}
$$

where $Y$ is the $Y$ value of the control point obtained from the important sampling, $f_{X}(x)$ is the NGSFLD function corresponding to the $X$ value of the control point, $n$ is the number of control points at $Z \leq 0$ and $N$ is the total number of control points. 
Since the control point is located at the weld and the weld is T-shaped, the GSFLD corresponding to Eqn. (10) should be selected as the standard for evaluating the fatigue strength of the control point. In order to compare the results of two fatigue strength evaluation standard, the fatigue strength of control points is calculated based on Eqn. (10) and traditional method, respectively, as illustrated in Fig. 14.

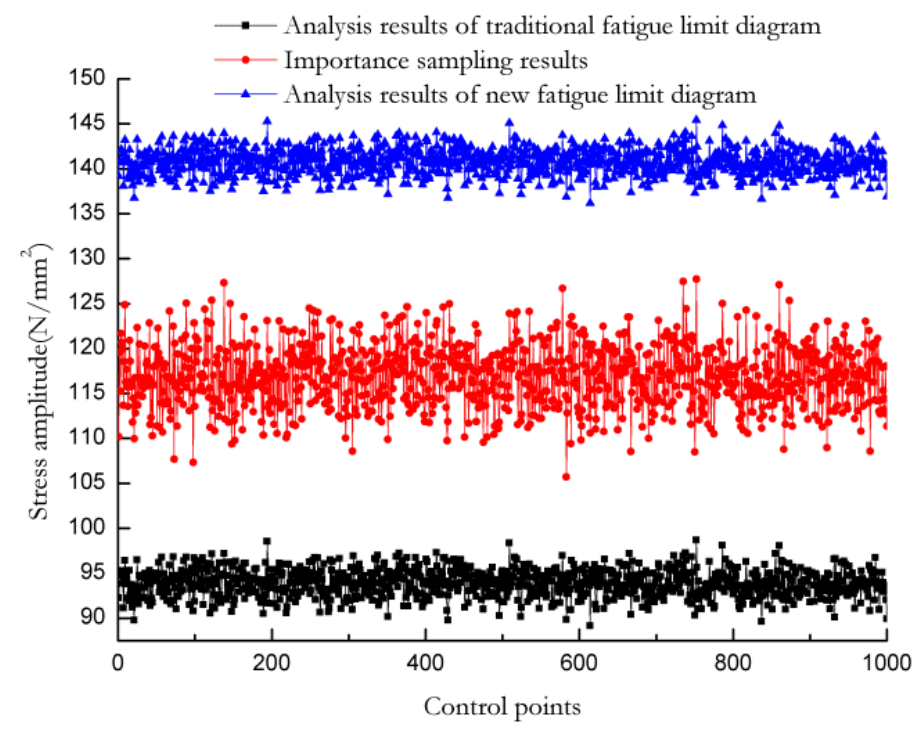

Figure 14: Comparison of fatigue strength analysis results of control points.
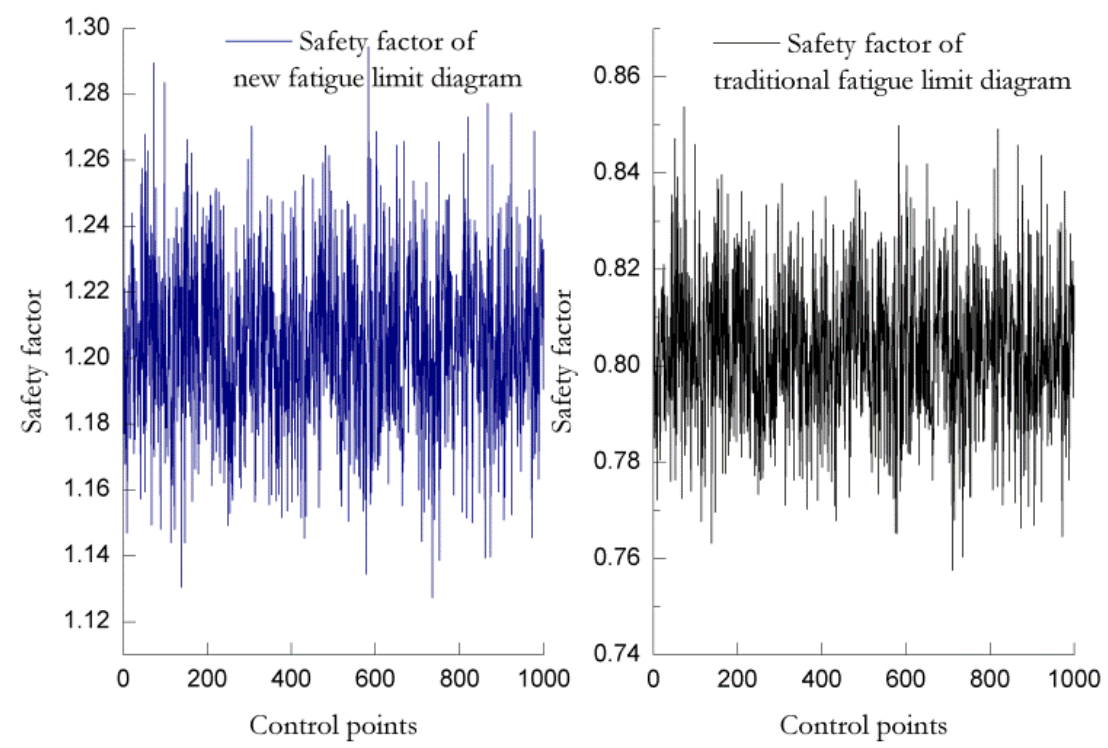

Figure 15: Comparison of safety factor of fatigue strength at control points.

From Fig. 14, it can be seen that the fatigue strength analysis results based on the NGSFLD are higher than the importance sampling results. Although the control points fluctuate to a certain extent due to the uncertainty of design parameters, the fatigue strength is still within the fatigue limit diagram, indicating that the fatigue strength of bogie frame basically meet the requirements. However, the results of fatigue strength analysis based on traditional method are lower than those of importance sampling. The reason is that the control point is beyond the scope of fatigue limit diagram when it is selected. Although the uncertainty of design parameters leads to the fluctuation of control points, all the results are still out of the fatigue limit diagram, indicating that the fatigue strength of bogie frame does not meet the requirements. In order to further analyze whether the fatigue strength meets the requirements or not, Fig. 15 plots the results of safety factor under two evaluation standards. It can be observed from the figure that the safety factors of the NGSFLD are all greater than 1.1, and basically remain at about 1.2. It meets the requirement of safety factor for fatigue strength analysis of bogie frame. On the contrary, the safety factors obtained by traditional method are less than 1, which does not meet the 
standard requirements, and the bogie frame needs to be redesigned and optimized. According to Eqn. (12), the reliability of bogie frame under the two evaluation standard is 1 and 0 , respectively. It shows that the fatigue limit diagram without considering safety factor can also be used to evaluate the bogie frame, and the traditional method has excessive safety factor, which is too conservative in design.

\section{CONCLUSIONS}

his paper presents a fatigue strength analysis method by considering uncertainty of design parameters based on GSFLD and reliability theory, and the practicability of the method is verified by employing NGSFLD for bogie frame. The proposed method solves the problem of conservatism in traditional fatigue strength analysis from two aspects: On the one hand, considering the uncertainty of design parameters, a parameterized model is established, and the fluctuation of control points under the uncertainty parameters is calculated. Compared with deterministic analysis, it can reflect the discreteness of analysis results caused by uncertainties such as design, manufacturing and working conditions. On the other hand, the fatigue limit diagram without considering safety factor is established. Compared with the fatigue limit diagram provided in ORE B12/RP17 standard, the excessive redundancy and conservative of the design scheme are solved. The fatigue strength reliability analysis results of the two methods are 1 and 0 , respectively. It shows that the traditional method is too conservative to evaluate the design scheme, which results in that the reliability of the original qualified design is 0 due to the high safety factor of the evaluation standard, which does not meet the requirements. It not only wastes resources, but also is not conducive to the lightweight design of railway vehicles. In general, in order to ensure the safety of structural design and achieve the purpose of lightweight design, the parameter uncertainty considered in the design stage is more consistent with the actual needs of the project.

\section{ACKNOWLEDGMENTS}

1 his research is supported by the National Natural Science Foundation of China under Contract No. 51875073, the Education Project of Liaoning Provincial Department under Contract No. JDL2017022, Liaoning Provincial Natural Science Foundation of China under Contract No. 20170540129.

\section{REFERENCES}

[1] Claus, H. and Schiehlen, W. (2007). Modeling and simulation of railway bogie structural vibrations, Veh. Syst. Dyn., 29(1), pp. 538-552. DOI: 10.1080/00423119808969585.

[2] Stichel, S. and Knothe, K. (2007). Fatigue life prediction for an s-train bogie, Veh. Syst. Dyn., 29(1), pp. 390-403. DOI: $10.1080 / 00423119808969573$.

[3] Ren, Z.S. and Xie, J.L. (2008). Influence on axle load to the service life of the crossbar set of railway freight car with equivalent load, J. Mech. Eng., 44(3), pp. 16-21. DOI: 10.3321/j.issn:0577-6686.2008.03.003.

[4] Zhu, N., Sun, S.G., Li, Q. and Zou, H. (2016). Theoretical research and experimental validation of elastic dynamic load spectra on bogie frame of high-speed train, Chin. J. Mech. Eng., 29(3), pp. 498-506.

DOI: 10.3901/CJME.2016.0308.027.

[5] Park, B.H. and Lee, K.Y. (2006). Bogie frame design in consideration of fatigue strength and weight reduction, Proceedings of the Institution of Mechanical Engineers, Part F: Journal of Rail and Rapid Transit, 220(3), pp. 201-206. DOI:10.1243/09544097f01405.

[6] Han, J.W., Kim, J.D. and Song, S.Y. (2013). Fatigue strength evaluation of a bogie frame for urban maglev train with fatigue test on full-scale test rig, Eng. Fail. Anal., 31, pp. 412-420. DOI:10.1016/j.engfailanal.2013.01.009.

[7] Hwa, P.B., Po, K.N., Seok, K.J. and Yong, L.K. (2006). Optimum design of tilting bogie frame in consideration of fatigue strength and weight, Veh. Syst. Dyn., 44(12), pp. 887-901. DOI:10.1080/00423110600737106.

[8] Seo, J.W., Hur, H.M., Jun, H.K., Kwon, S.J. and Lee, D.H. (2017). Fatigue Design Evaluation of Railway Bogie with Full-Scale Fatigue Test, Adv. Mater. Sci. Eng., 2017, pp. 1-11. DOI:10.1155/2017/5656497.

[9] Li, F.S., Wu, P.B., Zeng, J. and Wang, J.B. (2014). Study on the differences between the three common fatigue strength, J. Mech. Eng., 50(14), pp. 170-176. DOI: 10.3901/JME.2014.14.170. 
[10] Kim, J.S. (2006). Fatigue assessment of tilting bogie frame for Korean tilting train: Analysis and static tests, Eng. Fail. Anal., 13(8), pp. 1326-1337. DOI: 10.1016/j.engfailanal.2005.10.007.

[11] Wang, W.J., Li, Z.M., Li, Q. and Miao, L.X. (2009). Fatigue strength analysis of CRH2 motor bogie frame, Journal of Beijing Jiaotong University, 33(1), pp. 5-9. DOI: 10.3969/j.issn.1673-0291.2009.01.002.

[12] Wang, H., Liu, W.X. and Shang, Y.J. (2013). Fatigue strength analysis on welded frame of domestic Y25 bogie based on hot spot stress, China Railway Science, 34(4), pp. 66-70. DOI: 10.3969/j.issn.1001-4632.2013.04.11.

[13] Lu, Y.H., Feng, Z., Chen, T.L., Zeng, J. and Wu, P.B. (2014). Finite element analysis of multi-axial fatigue strength for railway vehicle bogie frame, Journal of Beijing Jiaotong University, 38(4), pp. 26-31.

DOI: $10.11860 /$ j.issn.1673-0291.2014.04.005.

[14] Lu, Y.H., Xiang, P.L., Zeng, J. and Chen, T.Z. (2016). Evaluation method of fatigue strength for welding bogie frame on railway vehicle, Journal Beijing Jiaotong University, 40(6), pp. 83-88. DOI: 10.11860/j.issn.1673-0291.2016.06.014.

[15] Elgendy, N.S., Ali, B.A. and Amr, S.S.A. (2016), Application of D-optimal design and RSM to optimize the transesterification of waste cooking oil using natural and chemical heterogeneous catalyst, Energy Sources, Part A: Recovery, Utilization, and Environmental Effects, 38(13), pp. 1852-1866. DOI: 10.1080/15567036.2014.967417.

[16] Olofsson, U. and Sundvall, K. (2004). Influence of leaf, humidity and applied lubrication on friction in the wheel-rail contact: Pin-on-disc experiments, Proceedings of the Institution of Mechanical Engineers, Part F: Journal of Rail and Rapid Transit, 218(3), pp. 235-242. DOI: 10.1243/0954409042389364.

[17] Zhi, P.P., Li Y.H. and Chen, B.Z. (2019). Structural strength analysis of bogie frames considering parameter uncertainty, Chin. Mech. Eng., 30(1), pp. 22-29. DOI: 10.3969/j.issn.1004-132X.2019.01.004.

[18] Zhao, H., Yue, Z., Liu, Y., Gao, Z., and Zhang, Y. (2015). An efficient reliability method combining adaptive importance sampling and kriging metamodel, Appl. Math. Modell., 39(7), pp. 1853-1866. DOI:10.1016/j.apm.2014.10.015.

[19] Lee, S., and Kim, J.H. (2017). An adaptive importance sampling method with a Kriging metamodel to calculate failure probability, J. Mech. Sci. Technol., 31(12), pp. 5769-5778. DOI: 10.1007/s12206-017-1119-8.

[20] Diao, Y., Shi, C., and Tian, H. (2016). Effect of multi-repair welding on fatigue performance of aluminum alloy profile welded joint, Mater. Sci. Eng., A, 2016, pp. 521-528. DOI: 10.1142/9789813141612_0071. 